Check for updates

Cite this: RSC Adv., 2019, 9, 6526

Received 26th September 2018 Accepted 10th February 2019

DOI: $10.1039 / \mathrm{c} 8 \mathrm{ra07997h}$

rsc.li/rsc-advances

\section{Inactivation of antibiotic-resistant bacteria by chlorine dioxide in soil and shifts in community composition}

\begin{abstract}
M. S. Wu (D) *abc and X. X ( $^{d}$
To study the efficacy of chlorine dioxide in the inactivation of antibiotic-resistant bacteria in soil, bacteria resistant to penicillin, amoxicillin or streptomycin were screened out from the soils around a hennery. The effects of dosage, contact time and $\mathrm{pH}$ value on the killing rates were investigated by batch experiments. The community composition before and after inactivation was analyzed by highthroughput genetic sequencing. The results showed that antibiotic-resistant bacteria are common and widespread in soil and the most resistant species is Staphylococcus aureus. More than $99 \%$ of antibioticresistant bacteria could be killed by chlorine dioxide at $5 \mathrm{mg} \mathrm{L}^{-1}$ within 30 min under neutral conditions. The killing log value declined slightly when the $\mathrm{pH}$ was changed from 4 to 9 . The dominant genus was Sphingomonas, which was sensitive to chlorine dioxide and could be inactivated easily similar to Arthrobacter and Massilia. However, Micromonosporaceae and Thaumarchaeota were more resistant to chlorine dioxide than other species, and their relative abundance increased after disinfection.
\end{abstract}

\section{Introduction}

Antibiotics have an essential role in controlling bacterial diseases in medical treatments and agriculture. They enter water and soil by the spreading of manure ${ }^{1}$ or by direct excretion from livestock. Antibiotics then enter deeper soil layers by surface runoff, driftage or leaching ${ }^{2}$ and finally accumulate in plants. $^{3}$ Many antibiotic-resistant bacteria (ARB) in soil have been found where livestock congregate. Manure application has significantly increased the diversity and abundance of antibiotic resistance genes (ARGs) in soil and also markedly shifted the bacterial composition that was significantly correlated with the ARG profiles. ${ }^{4}$ Uncontrolled use of antibiotics has led to the enrichment of ARGs in manure ${ }^{5}$ and affected environments, particularly soils. ${ }^{6}$ In the U.S., $60 \%$ to $80 \%$ of all antibiotics were used in animal production, and more than $80 \%$ of them were excreted in manure, ${ }^{7}$ which led to further pollution.

ARGs have been widely found in the soils of livestock areas. $\mathrm{Zhu}^{5}$ found 149 kinds of ARGs in the soils around three large farms, which were about 192-28 000 times higher than those found in soils without the use of antibiotics. Although antibiotic resistance may decline after the relaxation of selection

\footnotetext{
${ }^{a}$ College of Resources and Civil Engineering, Northeastern University, Shenyang 100819, China.E-mail: wumingsong@163.com

${ }^{b}$ School of Resources and Materials, Northeastern University at Qinhuangdao, Qinhuangdao, 066004, China

${ }^{c}$ Qinhuangdao Key Laboratory of Water Conservation and Pollution Control and Ecological Restoration, Qinhuangdao, 066004, China

${ }^{d}$ Tongji Zhejiang College, Jiaxing, 314051, China
}

pressures, low yet detectable levels of resistance determinants are likely to persist for decades. ${ }^{8}$ Also, the quantity of ARGs in the soil remains high even when the livestock has been removed from the site for two years. ${ }^{9}$

These ARB and ARGs from agricultural settings can be transferred to humans and become a critical health concern. ${ }^{\mathbf{1 0}}$ Completely antibiotic-resistant tuberculosis cases were reported in Iran in 2009 and India in 2011, independently. They were resistant to all the first- and second-line drugs. ${ }^{11}$ An analysis of 264 soil isolates obtained from different natural habitats in and around Hyderabad has identified 5 isolates that are resistant to as many as 10 antibiotics. ${ }^{12}$ Increased consumption of antibiotics may produce not only greater resistance at the individual patient level, but also greater resistance at community, country, and regional levels, which nevertheless can harm individual patients. ${ }^{13}$

It has been a hot topic to find out methods to slow or restrain spreading of drug resistance. ${ }^{\mathbf{1 4}}$ Most studies have reported the effect of various disinfection methods on ARB inactivation in water, and these methods include the use of ozone, ${ }^{15}$ chlorine, ${ }^{\mathbf{1 6}}$ and UV. However, UV and ozone disinfections result in apoptosis, and the bacterial DNA is released into the environment; then, ARGs are mostly found as free DNA in the treated wastewater. ${ }^{17}$ Very few studies are available about the effects of the disinfection process on the inactivation of ARB and ARGs in soils. Drug resistance to traditional disinfectants used in farms, such as phenol, formaldehyde, ${ }^{\mathbf{1 8}}$ sodium hypochlorite, calcium hypochlorite, ${ }^{19}$ and quaternary ammonium compounds, ${ }^{20}$ has been common due to the extensive application for many years. As the native soil bacterial species play a role in inhibiting the 
survival of $\mathrm{ARB}$ or dissemination of $\mathrm{ARGs},{ }^{21}$ the restoration of the microbial ecosystem after disinfection is also very important not only for soil function but also for reducing antibiotic resistance. Calcined eggshell amendment mitigated mixed pollutant accumulation in bell pepper significantly and enhanced the dissipation of soil tetracycline, sulfadiazine, roxithromycin, and chloramphenicol; it also decreased the watersoluble fractions of antibiotics and the diversity of ARB/ARGs inside the vegetables and contributed to the significant restoration of microbial biodiversity and stability. ${ }^{22}$

Chlorine dioxide $\left(\mathrm{ClO}_{2}\right)$ has been widely used for the inactivation of microorganisms and the removal of organic compounds as a substitute of chlorine for henhouse and cowshed disinfection and for other purposes in animal husbandry. ${ }^{23}$ After soaking in $\mathrm{ClO}_{2}$, the hatchabilities of eggs and duck eggs increase by $2 \%$ and $4 \%$, respectively, compared to that observed for fumigation with potassium permanganate and formaldehyde, ${ }^{24}$ and the incidence of zoonosis decreases. ${ }^{25}$ The $C_{\mathrm{t}} 99$ values of $\mathrm{ClO}_{2}$ and chlorine are similar for ARB, and the effects of $\mathrm{ClO}_{2}$ disinfection are not affected by ammonia nitrogen. ${ }^{\mathbf{1 4}}$ Chlorine dioxide also has an excellent effect on the inactivation of intracellular ARGs, ${ }^{26}$ which indicates that fewer ARGs would be released into the environment. Truchado ${ }^{27}$ found that the use of low residual $\mathrm{ClO}_{2}$ concentrations (approx. $0.25 \mathrm{mg} \mathrm{L}^{-1}$ ) to treat irrigation water decreases the relative abundance of Pseudomonadaceae (2.28-fold) and Enterobacteriaceae (2.5-fold) when comparing treated versus untreated baby spinach samples. Members of these two bacterial families are responsible for food spoilage and foodborne illnesses. ${ }^{28}$ There is still no report on $\mathrm{ClO}_{2}$ killing antibioticresistant bacteria directly in soil.

In this paper, the effect of $\mathrm{ClO}_{2}$ on the inactivation of $\mathrm{ARB}$ in soil near a henhouse was investigated, and the differences in the bacteria community before and after treatment were compared to provide a reference for the application of $\mathrm{ClO}_{2}$ to reduce ARB and ARGs in the soil.

\section{Materials and methods}

\section{Soil samples}

Soil samples were collected at 4 places in the gardens and vegetable fields that were $2 \mathrm{~km}$ away from a hennery located at 119.241672E and 39.871822N in Qinhuangdao City in China. All the soil samples were collected 10-15 cm underground and then screened through a 35 mesh sieve (with a particle size of $425 \mu \mathrm{m})$ after drying.

In order to investigate the antibiotic resistance under severe contamination pressure, the natural soil obtained above was mixed equally and then contaminated by antibiotics in the laboratory. Then, an antibiotic solution (penicillin, amoxicillin or streptomycin) was added into a $50 \mathrm{~mL}$ centrifuge tube (filled with $25 \mathrm{~mL}$ sterile water and $1 \mathrm{~g}$ mixed soil sample) at the concentration of $1,2.5,5.0,10$, or $50 \mathrm{mg} \mathrm{L}^{-1}$. The control group was prepared by the same procedure using sterilized water instead of antibiotics.

\section{Chemicals}

Chlorine dioxide was prepared by the reaction between $\mathrm{H}_{2} \mathrm{SO}_{4}$ and $\mathrm{NaClO}_{2}$ (eqn (1)) and absorbed by pure water.

$5 \mathrm{NaClO}_{2}+2 \mathrm{H}_{2} \mathrm{SO}_{4}=4 \mathrm{ClO}_{2}+2 \mathrm{Na}_{2} \mathrm{SO}_{4}+11 \mathrm{NaCl}+2 \mathrm{H}_{2} \mathrm{O}(1)$

Then, it was diluted and calibrated before use by sequential iodometry. ${ }^{29}$ Sodium thiosulfate solution $\left(0.05 \mathrm{~mol} \mathrm{~L}^{-1}\right)$, which was used to neutralize $\mathrm{ClO}_{2}$ at the end of the treatment process, was prepared by dissolving $7.9 \mathrm{~g}$ sodium thiosulfate in $1 \mathrm{~L} \mathrm{pH} 7$ buffer solution. All the $\mathrm{pH}$ buffer solutions ( $\mathrm{pH} 4-9)$ were prepared by using $\mathrm{KH}_{2} \mathrm{PO}_{4}$ and $\mathrm{Na}_{2} \mathrm{HPO}_{4}$. All the solutions were sterilized by autoclaving and stored at $4{ }^{\circ} \mathrm{C}$ before use.

\section{Screening of antibiotic-resistant bacteria}

Antibiotic-resistant bacteria were screened from natural soil and contaminated soil samples by using the plate streaking method. At first, $1 \mathrm{~g}$ of dried soil was soaked by $25 \mathrm{~mL}$ of sterile water. Then, it was centrifuged at $4000 \mathrm{rpm}$ for $5 \mathrm{~min}$. The bacterial supernatant prepared from different soils was then diluted 100-fold and spread onto 3 plates filled with nutrient agar medium. Three parallel plates were prepared for each sample. All the plates were incubated for $24 \mathrm{~h}$ at $37{ }^{\circ} \mathrm{C}$ in an HPS-400 biochemical incubator (Guowang Instruments Co., Ltd., Changzhou, China).

Antibiotic susceptibility was tested by the CLSI M100-S26 method using a drug resistance paper disc ${ }^{30}$ (Hangzhou Microbial Agent Ltd., product no. S1001 for penicillin, no. S1079 for amoxicillin and no. S1031 for streptomycin). The results were reported as sensitive (S), intermediate (I) and resistant (R). All the resistant strains were identified by culture and biochemical tests ${ }^{31}$ and the most resistant ARBs were further identified by 16 SrDNA sequences.

\section{Disinfection}

The effects of chlorine dioxide $\left(\mathrm{ClO}_{2}\right)$ on $\mathrm{ARB}$ inactivation were investigated by the suspension quantitative germicidal test. An ARB suspension was quantified by spectrophotometry at a wavelength of $530 \mathrm{~nm}$. Then, it was diluted to an absorbance of 0.350 before disinfection to keep the cell concentration at about $1 \times 10^{8} \mathrm{CFU}$ $\mathrm{mL}^{-1}$. The calibrated $\mathrm{ClO}_{2}$ solution was added by $1.0 \mathrm{~mL}$ pipette to a $10 \mathrm{~mL}$ centrifuge tube filled with $4.0 \mathrm{~mL}$ of different diluted ARB suspensions. Sterile water was used as a positive control. The tubes were put into a shaking table at a constant temperature. After a certain time, $1 \mathrm{~mL}$ of $0.05 \mathrm{~mol} \mathrm{~L}^{-1}$ buffered sodium thiosulfate was added to neutralise the remaining $\mathrm{ClO}_{2}$. Then, the plate counting method was used to count the residual bacterial after tenfold serial dilution. Three parallel samples were made for each antibiotic-resistant strain, and the thalli concentration was reported $(N)$. The killing log value (KL) was calculated by $\log \left(N_{0} / N_{x}\right)$. The killing rate $(\mathrm{KR})$ was calculated as $\mathrm{KR}=\left(1-10^{\mathrm{KL}}\right) \times 100 \%$.

\section{Sequencing of $16 \mathrm{~S}$ rRNA gene and bioinformatics analysis}

Disinfection was performed by adding $25 \mathrm{~mL} 15 \mathrm{mg} \mathrm{L}^{-1} \mathrm{ClO}_{2}$ to $50 \mathrm{~g}$ of the mixed soil sample collected in the wild. Then, it was 
centrifuged for $10 \mathrm{~min}$ at $4000 \mathrm{rpm}$. Total genomic DNA from the disinfected and raw soil samples was extracted using the CTAB/SDS method. DNA concentration and purity were monitored on $1 \%$ agarose gels. The $16 \mathrm{~S}$ rRNA genes of distinct regions (16SV4) were amplified using a specific primer $(515 \mathrm{~F}$ 806R) with the barcode.

All PCR reactions were carried out with Phusion ${ }^{\circledR}$ HighFidelity PCR Master Mix (New England Biolabs). We mixed the same volume of $1 \times$ loading buffer (containing SYB green) with PCR products and operated electrophoresis on $2 \%$ agarose gel for detection. Samples with a bright main strip between 400 and $450 \mathrm{bp}$ were chosen for further experiments. PCR products were mixed in equidensity ratios. Then, the mixture of PCR products was purified with a Qiagen Gel Extraction Kit (Qiagen, Germany). Sequencing libraries were generated using a TruSeq ${ }^{\circledR}$ DNA PCR-Free Sample Preparation Kit (Illumina, USA) following the manufacturer's recommendations and index codes were added. The library quality was assessed on a Qubit@2.0 Fluorometer (Thermo Scientific) and Agilent Bioanalyzer 2100 system. At last, the library was sequenced on an Illumina HiSeq2500 platform and 250 bp paired-end reads were generated. Paired-end reads were merged using V1.2.7 FLASH. ${ }^{32}$ Quality filtering on the raw tags was performed under specific filtering conditions to obtain the high-quality clean tags ${ }^{33}$ according to QIIME. ${ }^{34}$

Sequence analysis was performed by using Uparse software v7.0.1001. ${ }^{35}$ Sequences with $\geq 97 \%$ similarity were assigned to the same Operational Taxonomic Units (OTUs). For each representative sequence, the Green Gene Database ${ }^{36}$ was used based on an RDP classifier (version 2.2) 37 $^{37}$ algorithm to annotate the taxonomic information. The OTU abundance information was normalized using a standard of sequence number corresponding to the sample with the least sequences.

\section{Results}

\section{Antibiotic susceptibility of ARB}

ARB are found in every sample taken in different places irrespective of whether it is a natural or contaminated soil sample, and there is no significant difference. Bacteria that showed resistance to 3 kinds of antibiotics were found in all the samples, which indicated that resistance can be widely transferred. Moreover, 24 ARB strains were isolated from the soils (Table 1) altogether. Cross drug resistance was ubiquitous. All the penicillin-resistant strains were resistant to amoxicillin as amoxicillin is a kind of semi-synthetic penicillin.
The 7 strongest antibiotic resistant isolates were chosen for the disinfection experiment. P3, P4, and N6 isolates showed the strongest resistance to penicillin; A2 and N3 showed the strongest resistance to amoxicillin and S8 and N4 showed the strongest resistance to streptomycin. Their cross drug resistance is shown in Table 2. The results of the bacterial morphological examination indicated that all the colonies were round, smooth, non-transparent, faint yellow, neatly edged and wet. P3 and P4 were about 4-5 $\mathrm{mm}$ in diameter, and the others were about $3 \mathrm{~mm}$ in diameter. Based on 16S rDNA sequencing, all of the 7 isolates were found to be Staphylococcus aureus (SA).

\section{Disinfection efficacy of chlorine dioxide on ARB}

The effect of $\mathrm{ClO}_{2}$ dosage on disinfection was investigated at concentrations of $2,4,6,8$ and $10 \mathrm{mg} \mathrm{L}^{-1}$ at $25^{\circ} \mathrm{C}$ and $\mathrm{pH} 7.2$ for $30 \mathrm{~min}$. From the result in Fig. 1, it can be seen that the killing $\log$ values for all the antibiotic-resistant bacteria increase along with $\mathrm{ClO}_{2}$ dosages. Streptomycin-resistant bacteria were more resistant to $\mathrm{ClO}_{2}$ than penicillin- or amoxicillin-resistant bacteria. At $4 \mathrm{mg} \mathrm{L}^{-1}$ dosage of $\mathrm{ClO}_{2}$, $\mathrm{KL}$ values were 2.6, 2.7, 2.8 and 2.5 for P3, P4, N6, and A2, while they were only 2.2, 2.1 and 2.0 for N3, S8, and N4, respectively. The KL values increased to 2.0 and 2.1 for streptomycin-resistant bacteria $(\mathrm{S} 8, \mathrm{~N} 4)$ at a dosage of $6 \mathrm{mg} \mathrm{L}^{-1}$.

The kinetics of $\mathrm{ClO}_{2}$ inactivation of antibiotic-resistant bacteria was investigated by fitting the killing number using the Chick-Watson law (eqn (2)). The $C_{\mathrm{t}}$ values and $k$ values at $3 \log$ killing rate are listed in Table 3 . The $C_{\mathrm{t}}$ values were in the range of 23-28, which indicated that all the antibiotic-resistant bacteria could be easily killed by $\mathrm{ClO}_{2}$.

$$
\lg \frac{N_{t}}{N_{0}}=-k C_{\mathrm{t}}
$$

The experiments of the effect of contact time on disinfection were conducted at $5 \mathrm{mg} \mathrm{L}{ }^{-1} \mathrm{ClO}_{2}$ dosage and $\mathrm{pH}$ of 7.2. The suspension quantitative germicidal test was terminated by sodium thiosulfate after contacting for 5, 10, 15, 20 and $30 \mathrm{~min}$. From the results in Fig. 2, it can be seen that the KL values of all

Table 2 Cross-resistance of the strongest drug-resistant strains

\begin{tabular}{llllllllll}
\hline Strains & & P3 & P4 & N6 & A2 & N3 & S8 & N4 \\
\hline \multirow{2}{*}{ Antibiotic susceptibility } & Penicillin & R & R & R & R & R & R & R \\
& Amoxicillin & R & I & R & R & R & S & I \\
& Streptomycin & I & R & R & I & I & R & R
\end{tabular}

Table 1 Sensitive, intermediate and resistant antibiotic-resistant strains screened out by the CLSI M100-S26 method

\begin{tabular}{llllllll}
\hline & Sensitive & & & Intermediate & & \multicolumn{2}{c}{ Resistant } \\
\cline { 2 - 3 } & Natural soil & Contaminated soil & & Natural soil & Contaminated soil & Natural soil & Contaminated soil \\
\hline Penicillin & 0 & 4 & 0 & 2 & 6 & 4 \\
Amoxicillin & 0 & 0 & 2 & 3 & 2 & 6 & 1 \\
Streptomycin & 2 & 5 & & & 2 & 3 & 2
\end{tabular}




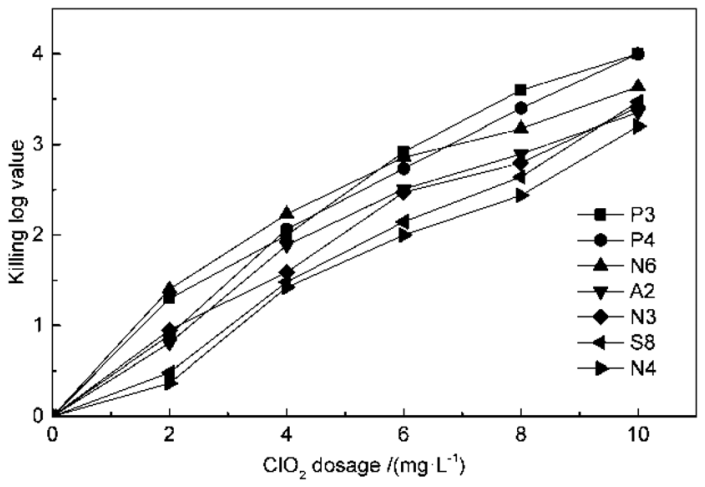

Fig. 1 Effect of $\mathrm{ClO}_{2}$ dosage on killing antibiotic-resistant bacteria.

Table 3 Bacteriolytic kinetics of $\mathrm{ClO}_{2}$ killing antibiotic-resistant bacteria at 3 log KL values

\begin{tabular}{lccccccc}
\hline & P3 & P4 & N6 & A2 & N3 & S8 & N4 \\
\hline$C_{\mathrm{t}}(3 \log )$ & 23.65 & 25.83 & 23.33 & 27.06 & 26.05 & 24.36 & 23.71 \\
$k$ & 0.127 & 0.116 & 0.129 & 0.111 & 0.115 & 0.123 & 0.127
\end{tabular}

the antibiotic-resistant bacteria increase for a contact time of 30 min. $\mathrm{P} 3, \mathrm{P} 4$, and $\mathrm{A} 2$ were killed by $\mathrm{ClO}_{2}$ quickly. The $\mathrm{KL}$ values of $\mathrm{P} 4$ and $\mathrm{A} 2$ almost reached 1.0 after contacting for 5 min, while those of $\mathrm{N} 3$ and $\mathrm{N} 4$ were just beyond 1.0 after $10 \mathrm{~min}$. The slopes of the KL value and contact time were all slightly down after $20 \mathrm{~min}$, which may be because $\mathrm{ClO}_{2}$ decreased with time.

The reactivation of ARB after disinfection was investigated at room temperature and under light conditions. The plates with 1 $\times 10^{8} \mathrm{CFU} \mathrm{mL}{ }^{-1}$ ARBs were treated by $5 \mathrm{mg} \mathrm{L}^{-1} \mathrm{ClO}_{2}$ for $30-$ $50 \mathrm{~min}$. The KL values of the 3 kinds of ARBs were all about $3 \mathrm{log}$. Then, they were calculated every 12 hours; the results are listed in Table 4. Twenty-four hours after $\mathrm{ClO}_{2}$ disinfection, all the $\mathrm{KL}$ values of ARBs were maintained at $3 \mathrm{log}$. Isolate $\mathrm{A} 2$ showed reactivation and regrowth at $36 \mathrm{~h}$, and its $\mathrm{KL}$ value decreased to 2.7. Then, P3 and P4 started reactivation and regrowth at $48 \mathrm{~h}$; their KL values were also 2.7 and that of A2 continued to decrease to 2.5 at the same time.

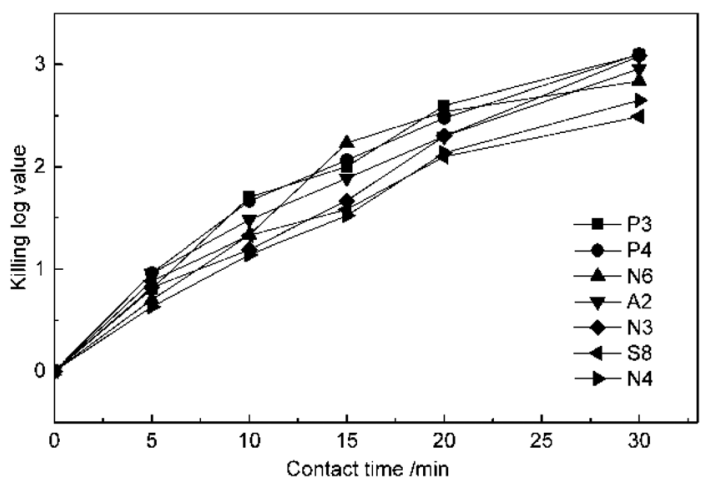

Fig. 2 Effect of contact time on antibiotic-resistant bacteria disinfection by $\mathrm{ClO}_{2}$.
Table 4 Average killing log values of antibiotic-resistant bacteria $24 \mathrm{~h}$ after disinfection

\begin{tabular}{llllllll}
\hline & \multicolumn{2}{l}{ Strains } & & & & & \\
\cline { 2 - 7 } Time/h & P3 & P4 & N6 & A2 & N3 & S8 & N4 \\
\hline 12 & 3 & 3 & 3 & 3 & 3 & 3 & 3 \\
24 & 3 & 3 & 3 & 3 & 3 & 3 & 3 \\
36 & 3 & 3 & 3 & 2.7 & 3 & 3 & 3 \\
48 & 2.7 & 2.7 & 3 & 2.5 & 3 & 3 & 3 \\
\hline
\end{tabular}

The effect of $\mathrm{pH}$ value was studied at $4 \mathrm{mg} \mathrm{L}^{-1} \mathrm{ClO}_{2}$ and 15 min by changing the $\mathrm{pH}$ value to $4,5,6,7,8$, and 9 using a phosphate buffer solution. The results in Fig. 3 indicate that the KL values slightly decrease in general in the $\mathrm{pH}$ range of 4-9. This may be because chlorite, a common by-product in $\mathrm{ClO}_{2}$ disinfection, is a kind of oxoacid group and has a higher redox potential under low $\mathrm{pH}$ conditions. The KL values for P3, P4, and N6 were higher than the others at $\mathrm{pH} 4$; then, those of $\mathrm{P} 3$, $\mathrm{P} 4$, and $\mathrm{N} 3$ decreased along with the increase in $\mathrm{pH}$ value, whereas the value for N6 first increased and then decreased. The KL values of S8 and N4 were not significantly affected until the $\mathrm{pH}$ value was raised to 9 , which is due to the disproportionation occurring for $\mathrm{ClO}_{2}$ beyond $\mathrm{pH} 9$. However, the effect of $\mathrm{pH}$ on $\mathrm{ClO}_{2}$ killing antibiotic-resistant bacteria was not significant in soil because the $\mathrm{pH}$ of common soils is between 4 and 9 .

\section{Analysis of bacterial community shift}

Total 45754 and 66360 effective tags were collected in the extracts of disinfected and raw soil samples, respectively, from which 1608 and 1654 OTUs were clustered and annotated. From the relationship of OTUs between the two samples as the Venn graph demonstrates in Fig. 4 and the relative abundance of the species described in Fig. 5, it can be seen that there is no great difference between the species in the soil before and after $\mathrm{ClO}_{2}$ disinfection. Proteobacteria dominated in both samples, followed by Actinobacteria. The relative abundances of Proteobacteria, Acidobacteria, Bacteroidetes, and Thaumarchaeota significantly decreased after disinfection, while those of Actinobacteria and Firmicutes increased.

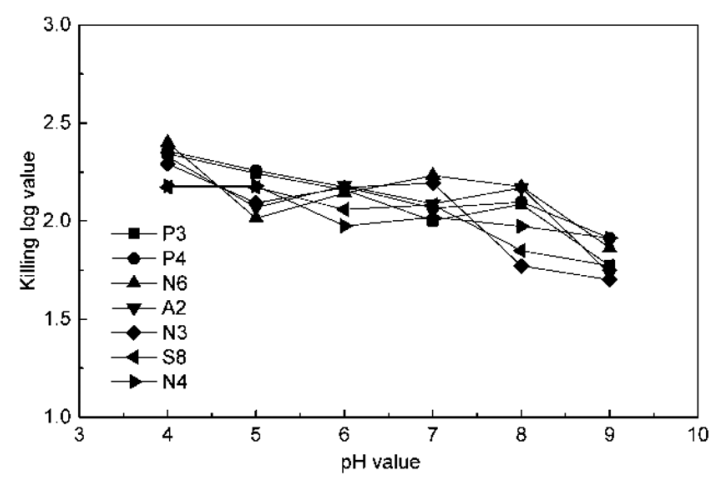

Fig. 3 Effect of $\mathrm{pH}$ on killing antibiotic-resistant bacteria. 


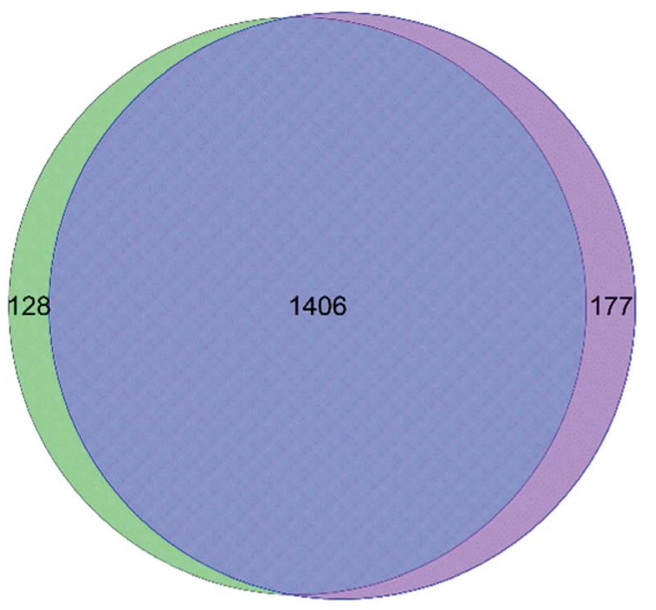

Raw soil sample $\quad$ Disinfected soil sample

Fig. 4 Venn graph of clustered OTUs between the disinfected and the raw soil samples.

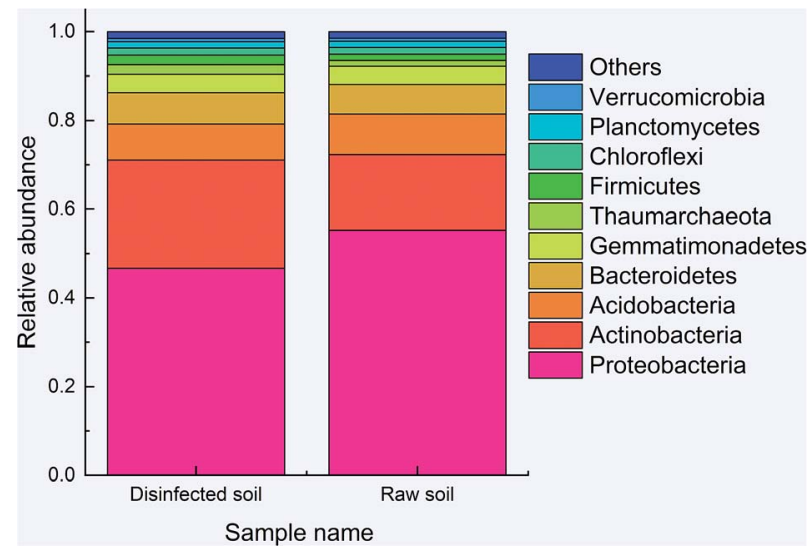

Fig. 5 The relative abundance of the species between disinfected and raw samples at the kingdom level.
The 50 most abundant OTUs in the heat map of Fig. 6 illustrate highly similar profiles of OTU frequencies for both samples, in which $\mathrm{S} 1$ represents a disinfected soil sample and S2 represents a raw sample. The dominant species in both samples were Arthrobacter oxydans and Sphingomonas, whose relative abundances decreased by $48 \%$ and $55 \%$, respectively, after $\mathrm{ClO}_{2}$ disinfection (from 1035 sequences to 636 and $346+$ $990+461+320$ to $188+502+285+185$, respectively). The amounts of Paucimonas, Massilia timonae, and other species belonging to Sphingomonadales and Piscinibacter were also reduced. Furthermore, the relative abundance of Micromonosporaceae increased mostly (from 98 to 494) and that of Blastococcus also increased significantly (from 330 to 547). Other major species that increased after disinfection were Steroidobacter (from 225 to 396), Microvirga (from 241 to 390), and Thaumarchaeota (from 181 to 321 ).

\section{Discussion}

From the results mentioned above, we inferred that all the strains found in soil and having the strongest resistance were Staphylococcus aureus and not Escherichia coli, as reported before. ${ }^{38-40}$ Staphylococcus aureus is a major pathogenic microorganism responsible for a series of infections. In particular, methicillin-resistant Staphylococcus aureus (MRSA) exists all around the world and has become a major pathogenic microorganism in hospitals and community. ${ }^{41}$ Penicillin, amoxicillin, and streptomycin are 3 kinds of antibiotics that are commonly used in animal husbandry in China. Therefore, this proves that antibiotics are no longer as effective as before, and their longterm use has led to serious drug resistance. ${ }^{42}$

Chlorine dioxide can inactivate ARBs effectively and is an effective agent for soil disinfection. Although there have been many reports about $\mathrm{ClO}_{2}$ inactivation of ARB and ARGs in water and wastewater in recent years, there is no such study about soil disinfection and no mention of multi-drug resistant MRSA. Judging by the $3 \log C_{\mathrm{t}}$ values, $\mathrm{ClO}_{2}$ is a highly efficient

Consensus Lineage

k Bacteria;p Actinobacteria;c unidentified Actinobacteria;o Micrococcales;f Micrococcaceae;g Arthrobacter;s Arthrobacter_oxydans

k_Bacteria; $p$ __Proteobacteria;c_Betaproteobacteria; 0 _Burkholderiales;f_Oxalobacteraceae; $g$ _Paucimonas; $\mathbf{s}$

k_Bacteria;p_Actinobacteria;c_unidentified_Actinobacteria;o_Frankiales;f_Geodermatophilaceae;g_Blastococcus;s_

k Bacteria;p Proteobacteria;c Betaproteobacteria;o Burkholderiales; $f$ Comamonadaceae;g Ramlibacter;s

k_Bacteria;p_Proteobacteria;c_Betaproteobacteria;o_Burkholderiales;f_Oxalobacteraceae;g_Massilia;s_Massilia_timonae

k_Archaea;p_Thaumarchaeota;c_.SCG.;0_;f_g_;s

k_Bacteria; $p$ _Proteobacteria;c_Alphaproteobacteria; 0 Sphingomonadales;f_Sphingomonadaceae;g_Sphingomonas

k__Bacteria;p__Proteobacteria;c__Gammaproteobacteria;o__Xanthomonadales;f__unidentified_Xanthomonadales;g_Steroidobacter;s_

k__Bacteria; $p$ __Proteobacteria;c__Alphaproteobacteria; $0 \_$Rhizobiales; $f$ Methylobacteriaceae; $g$ _Microvirga;s

k_Bacteria; $p \_$Proteobacteria;c__Alphaproteobacteria;o__Sphingomonadales;f_Sphingomonadaceae;g_Sphingomonas;s_

k_Bacteria;p__Proteobacteria;c___Alphaproteobacteria;o_Sphingomonadales

K_Bacteria;p_Actinobacteria;c_unidentified_Actinobacteria;o_Micrococcales;f_Micrococcaceae;g_Kocuria;s_Kocuria_rosea

k__Bacteria;p__Proteobacteria;c__Betaproteobacteria;o_Nitrosomonadales;f_Nitrosomonadaceae;g__s_

k_Bacteria; ___Acidobacteria;c_unidentified_Acidobacteria;o_Subgroup_4;f_RB41;g_;s_

k_Bacteria;p_Proteobacteria; $c$ Alphaproteobacteria; 0 Sphingomonadales; $;$ Sphingomonadaceae;g Sphingomonas

k_Bacteria; $p$ __Actinobacteria;c_unidentified_Actinobacteria; $0 \_$Micromonosporales;f_Micromonosporaceae

k_Bacteria;p_Proteobacteria;c__Alphaproteobacteria;o_Sphingomonadales;f_Sphingomonadaceae;g_Sphingomonas

k Bacteria;p Proteobacteria;c Betaproteobacteria;o Burkholderiales; f Comamonadaceae;g Piscinibacter;s

k_Bacteria; $p$ __Proteobacteria;c_Betaproteobacteria;o_Burkholderiales;f_Comamonadaceae;g_Azohydromonas

Fig. 6 Heat map of species annotation results of disinfected (S1) and raw (S2) soil samples. The numbers indicate the amount of sequences of the OTU in the sample and the colour represents the number of sequences of the OTU in the sample. 
disinfectant not only for water but also for soil. Chlorine dioxide is more suitable for soil disinfection than $\mathrm{NaClO} .{ }^{43}$ It evaporates rapidly from an aqueous solution as a gas and then permeates the soil to contact and kill bacteria. However, $\mathrm{HOCl}$ and other liquid disinfectants have less permeability in the soil. ${ }^{44}$ As the $\mathrm{pH}$ range of common soil is about $5-8$, the effect of $\mathrm{pH}$ on the disinfection is negligible.

There is no great difference between the species in the soil before and after $\mathrm{ClO}_{2}$ disinfection; this is consistent with the results of Truchado's study, ${ }^{\mathbf{4}}$ in which the abundance of Proteobacteria (the major genus), Pseudomonadaceae and Enterobacteriaceae decreased when comparing samples that were treated and untreated with $\mathrm{ClO}_{2}$. It has also been reported that Proteobacteria, Firmicutes, and Planctomycetes are tolerant of chlorine in the secondary effluent of wastewater treatment plants. ${ }^{45}$ Also, the relative abundances of Pseudomonas and Sphingomonas increase in the drinking water disinfection process after chlorination. ${ }^{46}$ This is similar to the results observed for the use of $\mathrm{ClO}_{2}$ in this study as phylum Planctomycetes is a kind of aquatic bacterium. Sphingomonas is sensitive to $\mathrm{ClO}_{2}$ but not to chlorine. ${ }^{47}$ This may be due to the good penetrating ability of chlorine dioxide, which can penetrate the fatty acid structure of the cell membrane of Sphingomonas. ${ }^{48}$ Thus, the result suggests that $\mathrm{ClO}_{2}$ is a better disinfectant for soil disinfection treatments than chlorine.

It should be noted that in this study, we only investigated the characteristics and changes in ARB in the soil during $\mathrm{ClO}_{2}$ disinfection. The ability of $\mathrm{ClO}_{2}$ to destroy ARGs still needs to be studied further.

\section{Conclusion}

In this study, we identified bacterial species that are resistant to penicillin, amoxicillin, and streptomycin in the soil around a hennery and the disinfection efficiency of $\mathrm{ClO}_{2}$ on them. Bacteria resistant to penicillin, amoxicillin and streptomycin are common in natural soils. Staphylococcus aureus exhibited the strongest resistance. All the bacteria resistant to penicillin were also resistant to amoxicillin. $\mathrm{ClO}_{2}$ could inactivate $\mathrm{ARB}$ in soils effectively, and the effect of $\mathrm{pH}$ value was not significant. Micromonosporaceae and the identified species in Thaumarchaeota were more resistant to $\mathrm{ClO}_{2}$ than Sphingomonas, Arthrobacter and Massilia. At the phylum and class levels, no significant differences in the bacterial communities were observed between the untreated and $\mathrm{ClO}_{2}$-treated soil samples. Sphingomonas was the dominant genus in the soil before and after treatment by $\mathrm{ClO}_{2}$. Based on the results obtained, $\mathrm{ClO}_{2}$ could be considered as a suitable disinfectant for ARB in soil.

\section{Conflicts of interest}

There are no conflicts to declare.

\section{Acknowledgements}

The authors gratefully acknowledge funding support by the Key Research and Development Plan of Jiangxi of China
(20171BBG70035) and the Chinese Universities Scientific Fund (N172304046).

\section{Notes and references}

1 S. Peng, Y. Wang, B. Zhou and X. Lin, Sci. Total Environ., 2015, 506-507, 279-286.

2 N. Kemper, Ecol. Indic., 2008, 8, 1-13.

3 X. Hu, Q. Zhou and Y. Luo, Environ. Pollut., 2010, 158, 29922998.

4 Q. L. Chen, X. L. An, H. Li, Y. G. Zhu, J. Q. Su and L. Cui, Soil Biol. Biochem., 2017, 114, 229-237.

5 Y. G. Zhu, T. A. Johnson, J. Q. Su, M. Qiao, G.-X. Guo, R. D. Stedtfeld, S. A. Hashsham and J. M. Tiedje, Proc. Natl. Acad. Sci. U. S. A., 2013, 110, 3435-3440.

6 N. Wu, M. Qiao, B. Zhang, W. D. Cheng and Y. G. Zhu, Environ. Sci. Technol., 2010, 44, 6933-6939.

7 E. Cytryn, Soil Biol. Biochem., 2013, 63, 18-23.

8 P. Amy, D. G. Larsson Joakim, A. Alejandro, C. Peter, K. Brandt Kristian, D. W. Graham, M. Lazorchak James, S. Suzuki, S. Peter, R. Snape Jason, E. Topp, T. Zhang and Y.-G. Zhu, Environ. Health Perspect., 2013, 121, 878-885.

9 L. M. Durso and K. L. Cook, Curr. Opin. Microbiol., 2014, 19, 37-44.

10 V. Economou and P. Gousia, Infect. Drug Resist., 2015, 8, 49. 11 Z. F. Udwadia, R. A. Amale, K. K. Ajbani and C. Rodrigues, Clin. Infect. Dis., 2012, 54, 579-581.

12 S. Sengupta and M. K. Chattopadhyay, Resonance, 2012, 17, 177-191.

13 B. G. Bell, F. Schellevis, E. Stobberingh, H. Goossens and M. Pringle, BMC Infect. Dis., 2014, 14, 13.

14 Y. Zhang, Y. Zhuang, J. Geng, H. Ren, Y. Zhang, L. Ding and K. Xu, Sci. Total Environ., 2015, 512-513, 125-132.

15 N. Czekalski, S. Imminger, E. Salhi, M. Veljkovic, K. Kleffel, D. Drissner, F. Hammes, H. Bürgmann and U. von Gunten, Environ. Sci. Technol., 2016, 50, 11862-11871.

16 J. J. Huang, H. Y. Hu, F. Tang, Y. Li, S. Q. Lu and Y. Lu, Water Res., 2011, 45, 2775-2781.

17 J. Zheng, C. Su, J. Zhou, L. Xu, Y. Qian and H. Chen, Chem. Eng. J., 2017, 317, 309-316.

18 P. Gilbert and A. J. McBain, Clin. Microbiol. Rev., 2003, 16, 189-208.

19 H. F. Ridgway and B. H. Olson, Appl. Environ. Microbiol., 1982, 44, 972-987.

20 S. Buffet-Bataillon, P. Tattevin, M. Bonnaure-Mallet and A. Jolivet-Gougeon, Int. J. Antimicrob. Agents, 2012, 39, 381389.

21 S. Peng, B. Zhou, Y. Wang, X. Lin, H. Wang and C. Qiu, Biol. Fertil. Soils, 2016, 52, 655-663.

22 M. Ye, M. Sun, Y. Feng, X. Li, A. P. Schwab, J. Wan, M. Liu, D. Tian, K. Liu, J. Wu and X. Jiang, J. Agric. Food Chem., 2016, 64, 5446-5453.

23 C. N. Cutter and W. J. Dorsa, J. Food Prot., 1995, 58, 12941296.

24 P. H. Patterson, S. C. Ricke, M. L. Sunde and D. M. Schaefer, Avian Dis., 1990, 34, 1-6. 
25 M. E. Berrang, N. A. Cox, J. F. Frank, R. J. Burh and J. S. Bailey, J. Appl. Poult. Res., 2000, 9, 279-284.

26 P. Zhou, S. Li and M. C. Dodd, Proceedings of the Water Environment Federation, 2013, 2013, 131-135.

27 P. Truchado, M. I. Gil, T. Suslow and A. Allende, PLoS One, 2018, 13, e0199291.

28 J. Mansfield, S. Genin, S. Magori, V. Citovsky, M. Sriariyanum, P. Ronald, M. Dow, V. Verdier, S. V. Beer, M. A. Machado, I. Toth, G. Salmond and G. D. Foster, Mol. Plant Pathol., 2012, 13, 614-629.

29 M. Wu, J. Liu, S. You, L. Wang, J. Huang and Y. Tian, Environ. Eng. Sci., 2012, 29, 133-138.

30 M. J. Ferraro, Performance standards for antimicrobial susceptibility testing, Clinical and Laboratory Standards Institute, Wayne, PA, 26th edn, 2016.

31 G. Garrity, Bergey's Manual of Systematic Bacteriology Volume 2: The Proteobacteria, Springer US, New York, 2005, vol. 2.

32 T. Magoč and S. L. Salzberg, Bioinformatics, 2011, 27, 29572963.

33 N. A. Bokulich, S. Subramanian, J. J. Faith, D. Gevers, J. I. Gordon, R. Knight, D. A. Mills and J. G. Caporaso, Nat. Methods, 2013, 10, 57-59.

34 J. G. Caporaso, J. Kuczynski, J. Stombaugh, K. Bittinger, F. D. Bushman, E. K. Costello, N. Fierer, A. G. Peña, J. K. Goodrich, J. I. Gordon, G. A. Huttley, S. T. Kelley, D. Knights, J. E. Koenig, R. E. Ley, C. A. Lozupone, D. McDonald, B. D. Muegge, M. Pirrung, J. Reeder, J. R. Sevinsky, P. J. Turnbaugh, W. A. Walters, J. Widmann, T. Yatsunenko, J. Zaneveld and R. Knight, Nat. Methods, 2010, 7, 335-336.

35 R. C. Edgar, Nat. Methods, 2013, 10, 996-998.

36 T. Z. DeSantis, P. Hugenholtz, N. Larsen, M. Rojas, E. L. Brodie, K. Keller, T. Huber, D. Dalevi, P. Hu and G. L. Andersen, Appl. Environ. Microbiol., 2006, 72, 50695072.
37 Q. Wang, G. M. Garrity, J. M. Tiedje and J. R. Cole, Appl. Environ. Microbiol., 2007, 73, 5261-5267.

38 C. S. Riesenfeld, R. M. Goodman and J. Handelsman, Environ. Microbiol., 2004, 6, 981-989.

39 S. Demanèche, H. Sanguin, J. Poté, E. Navarro, D. Bernillon, P. Mavingui, W. Wildi, T. M. Vogel and P. Simonet, Proc. Natl. Acad. Sci. U. S. A., 2008, 105, 3957-3962.

40 R. Marti, A. Scott, Y.-C. Tien, R. Murray, L. Sabourin, Y. Zhang and E. Topp, Appl. Environ. Microbiol., 2013, 79, 5701-5709.

41 S. R. Harris, E. J. Feil, M. T. G. Holden, M. A. Quail, E. K. Nickerson, N. Chantratita, S. Gardete, A. Tavares, N. Day, J. A. Lindsay, J. D. Edgeworth, H. de Lencastre, J. Parkhill, S. J. Peacock and S. D. Bentley, Science, 2010, 327, 469-474.

42 A.-P. Magiorakos, A. Srinivasan, R. B. Carey, Y. Carmeli, M. E. Falagas, C. G. Giske, S. Harbarth, J. F. Hindler, G. Kahlmeter, B. Olsson-Liljequist, D. L. Paterson, L. B. Rice, J. Stelling, M. J. Struelens, A. Vatopoulos, J. T. Weber and D. L. Monnet, Clin. Microbiol. Infect., 2012, 18, 268-281.

43 A. Hinenoya, S. P. Awasthi, N. Yasuda, A. Shima, H. Morino, T. Koizumi, T. Fukuda, T. Miura, T. Shibata and S. Yamasaki, Jpn. J. Infect. Dis., 2015, 68, 276-279.

44 Z. Noszticzius, M. Wittmann, K. Kály-Kullai, Z. Beregvári, I. Kiss, L. Rosivall and J. Szegedi, PLoS One, 2013, 8, e79157. 45 Y. C. Pang, J. Y. Xi, Y. Xu, Z. Y. Huo and H. Y. Hu, Appl. Microbiol. Biotechnol., 2016, 100, 6435-6446.

46 S. Jia, P. Shi, Q. Hu, B. Li, T. Zhang and X. X. Zhang, Environ. Sci. Technol., 2015, 49, 12271-12279.

47 W. Sun, W. Liu, L. Cui, M. Zhang and B. Wang, Sci. Total Environ., 2013, 458-460, 169-175.

48 Y. Q. Chen, X. D. Duan, P. P. Lu, Q. Wang, X. J. Zhang and C. Chen, Huanjing Kexue, 2012, 33, 104-109. 